\title{
Trends in Contraceptive Use and Method Mix from Equity Perspective in the Past Two Decades: Evidence from Two East Indian States
}

\author{
Ranjan Kumar Prusty ${ }^{1 *}$, Amit Bhanot ${ }^{2}$, Hanimi Reddy ${ }^{3}$ and Ranjan Kumar Panda ${ }^{4}$ \\ ${ }^{1}$ IIHMR University, India
}

${ }^{2}$ Project Director and Senior Regional Health Advisor for Asia and Africa at Palladium, India

${ }^{3} \mathrm{M} \&$ E expert save the children, India

${ }^{4}$ State team leader at Palladium, India

Submission: February 02, 2018; Published: March 23, 2018

*Corresponding author: Ranjan Kumar Prusty, Assistant Professor, IIHMR University, India; Email: prustyranjan2006@gmail.com

\begin{abstract}
Method: mix is a key determinant of the fertility impact of contraceptive practices; the use of effective and right methods by couples can produce a greater decline in fertility than use of less effective methods. The present paper tries to understand contraceptive use with a special focus on spacing methods in the state of Bihar and Odisha during 1992-2014. Indian National Family Health Surveys (NFHS) of 1992-93, 1998-99 and 2005-06 and project Ujjwal Survey data (2014) in Bihar and Odisha were used in the analyses. Data on currently married fecund women were used for the present study. Both bivariate and multivariate analysis was used to understand the changes in different methods and factors associated with the methods. The results show there is an increase in contraceptive prevalence rate both nationally (1992-2006) and in both the states (19922014). The share of sterilization has increased in the high fertility state of Bihar whereas it has gone down in moderate fertility state of Odisha. There is a steady increase in short-term modern methods in Odisha largely contributing to its increase in contraceptive prevalence whereas in Bihar the spacing methods don't show a clear pattern. The multivariate analysis shows the predicated probability of using modern spacing method is lowest among Muslims, Poor and older women in both the states in both the states after adjusting socio-economic variables. This paper brought the significance of method-mix in contraceptive prevalence in the states. The initiatives by NGOs and experiments with public-private partnerships are one of the leading contributors to increase in spacing methods. The social marketing and social franchising of selected reproductive health services by project Ujjwal is one such example. Similar initiatives on prioritizing spacing methods in family planning may be successful in improving access to contraceptive in Bihar.
\end{abstract}

Abbreviations : NFHS: National Family Health Surveys; IUD: Intra-Uterine Device; ICPD: International Conference on Population and Development; MDG: Millennium Development Goal; CPR: Contraceptive Prevalence Rate; mCPR: Modern Contraceptive Prevalence Rate; TMA: Total Market Approach; FP: Family Planning; PCA: Principal Component Analysis; SCs: Scheduled Castes; STs: Scheduled Tribes; OBCs: Other Backward Castes; BPL: Below Poverty Line

\section{Background}

Contraceptive choice is a vital element of quality of care in the provision of family planning services and an important dimension of women's reproductive rights [1]. In 1951, India was the first country to adopt a national family planning programme. Since its initiation female sterilization is the most widely used method as compared to spacing methods like Intra-Uterine Device (IUD), condoms, pills etc. As a one-time measure, it is seen as the best contraceptive by Indian policy makers who moved to a radically different policy of forced sterilization within a very short time span (1975-77) to achieve population stabilization in India. The target oriented approach led to all staff working in the field of family planning being judged by the number of 'tubectomies' they delivered in a year (twenty point programme of the 1980's). The 20-Point Programme lunched on 1975 and subsequently revised in 1982 is aimed to eradicate poverty and to improve the quality of life of the poor and the under privileged population of the country. The programme covers various socioeconomic aspects which includes health and family planning. The target free approach during the reproductive and child health regime restored some degree fee and fair choice which was adopted after the International Conference on Population and Development (ICPD) in Cairo in 1994. An integrated approach was adopted through National Rural Health Mission (2005) to 


\section{Global Journal of Reproductive Medicine}

promote both limiting and spacing methods. However, method mixing in family planning remains a goal for many states in India due use low spacing methods.

\section{Method}

Mix is a key determinant of the fertility impact of contraceptive practice; the use of more effective and right methods by eligible couples can produce a greater decline in fertility than use of less effective methods by couples [2]. The study by Ross \& Stover [3] found that use of modern contraception increases when more methods become available. A Taiwan analysis showed a significant rise in the duration of contraceptive use when family planning programs began offering multiple methods, estimating that the addition of one method would increase total contraceptive use by about 12 percentage points (from $30 \%$ to $42 \%$ ) [4]. A simulation study demonstrated the limitations of any one method, noting that the usual discontinuation rate for a method would leave users with no alternative protection for their remaining reproductive years, except to have multiple abortions [5]. Female sterilization which is the dominant method in India is certainly not a method of choice for young women because they may need temporary methods. In the face of a lack of choices, many young women prefer to have two children in quick succession and then opt for an early tubectomy. In Andhra Pradesh, median age at sterilization is as low as 23 years in 20062007. Encouraging couples to delay sterilization is an important option that India explore in order to prevent subsequent regret amongst couples [6]. There are cases of women as young as 21 undergoing tubal ligation after having two children. Research indicates that tubectomy at very young age is undesirable and women under the age of 30 should be provided with other choices due to existing risk of sterilization failure and menstrual abnormalities [7].

\section{Trends in contraceptive prevalence rate (CPR) in India}

Family planning was important to fifth Millennium Development Goal (MDG) which focuses on improving maternal health (MDG 5) and certainly needed to be greatly focused on to achieve Sustainable Development Goals (SDGs)- Goal 2 (ensure healthy life and promote well being for all at all ages) and Goal 5 (achieve gender equality and empower all women and Girl). To realize the SDGs and FP 2020 commitments to achieve 48 million new users by 2020 (against 2012), the Indian government announced the expansion of the basket of contraceptive choice for women with the introduction of injectables, and improved quality health care in the country. During the last five decades (1970-2008), contraceptive usage has grown remarkably and has more than quadrupled (from $13 \%$ of married women in 1971 to $55 \%$ in 2007-08) but the limiting methods still remains a dominant method contributing more than $75 \%$ of CPR of modern methods [8]. Additionally, there exist large-scale variations and diversities in the demographic characteristics of users and in the socio- economic and cultural contexts of use between and within the states and regions of the country. The modern contraceptive prevalence rate (mCPR) among married women remains very low in most of the northern and eastern states which is relatively lower than the southern and western states [8]. There is also a large difference in contraceptive use by socioeconomic groups in the country $[9,10]$. Limited access to contraception forces unintended pregnancies and unsafe abortions thereby puts many women at the risk of maternal deaths [11].

Bihar and Odisha are two states in eastern part of India with similar socio-economic and demographic profile. The two states are having highest proportion of households under below poverty line and have very high maternal and child mortality rates. While Bihar has the highest total fertility rates in India, Odisha is moderate fertility with high infant and mortality. Odisha has modern contraceptive prevalence rate (mCPR) of 40 percent while Bihar MCPR is as low as 29 percent. As evidence suggests positive linkages between modern CPR and demographic indicators such as fertility, maternal and child mortality, the call to increase in mCPR in these states are most justified [12] (Table 1). The CPR is these states in lower side and is highly dependent on government facilities which are insufficient to meet the contraceptive needs of couples in both the states especially in Bihar. The private sector can be one of the successfully partner in strengthening the contraceptive use in the states and this approach which has successfully implemented in some of the countries to enhance the contraceptive use is termed as total market approach or TMA.

Table 1: Socio-economic and Demographic Profile of Bihar and Odisha.

\begin{tabular}{|c|c|c|}
\hline Socio-economic Profile & Odisha & Bihar \\
\hline Total Population, 2011 & $41,974,218$ & $104,099,452$ \\
\hline Density Per Sq. Km, 2011 & 269 & 1106 \\
\hline Area (in sq. Km) & 155,707 & 94,163 \\
\hline Total Fertility Rate, SRS 2011 & 2.2 & 3.6 \\
\hline mCPR, DLHS-III, 2007-08 & 39.6 & 29.4 \\
\hline IMR, SRS-2014 & 51 & 42 \\
\hline MMR, SRS-2013 & 235 & 219 \\
\hline Literacy rate, 2011 & 72.87 & 61.8 \\
\hline GDP (in billions) & $\$ 40$ & $\$ 50$ \\
\hline
\end{tabular}

The TMA has been implemented in Nicaragua, Vietnam, Eastern Europe, and Central Asia to create a sustainable model to make contraceptives available to even the poorest citizens $[13,14]$. The above countries are applying a total market approach (TMA) that directs people who can pay for services to the private sector, freeing up public resources for those most in need and increasing family planning access to consistently underserved populations. The paper presented here seek to understand contraceptive use with a special focus on spacing methods in the high fertility state of Bihar and moderate fertility state of Odisha during the period of 1992-2014. This paper focuses on wealth quintile based approach to study public-private partnership in family planning in both the states. 


\section{Global Journal of Reproductive Medicine}

\section{Data and methods}

Multiple data sources were used in the current study looking at strength and limitation of datasets and methods used. Data from household surveys on health and nutrition including the Indian National Family Health Surveys (NFHS) of 1992-93, 199899 and 2005-06 and baseline survey of project Ujjwal conducted on 2014 in Bihar and Odisha were used for trend analysis and socio-economic differentials. The NFHS is Indian version of Demographic Health Survey and is the standardized survey over 80 countries with over 240 surveys worldwide. While the NFHS surveys were conducted nationally and the project Ujjwal Baseline survey was conducted in the state of Bihar and Odisha using probability proportionate sampling. NFHS is Indian form of Demographic Health Survey which provide reliable estimates on fertility, family planning, utilization of maternal and child healthcare services, nutritional status of children and women, and infant mortality at national level, state level and separately for urban and rural areas. All three rounds of the survey adopted multi-stage sampling design - two stage sampling design in rural areas and three-stage in urban areas. The sampling design remained similar in all the three rounds of the surveys which allow a comparison with the estimates of consecutive rounds [15]. The details of sampling design are given in the reports of the various rounds of NFHS [16]. Data for Bihar and Odisha is extracted from the national survey for the current analysis.

Project Ujjwal baseline household survey was conducted in 2014 to know different indicators of contraception in Bihar and Odisha. UK Aid launched project Ujjwal in a bid to improve reproductive, maternal and newborn health in Bihar and Odisha with special focus on promoting the use of family planning methods. The project aims at preventing unsafe abortions in Odisha and Bihar and reducing maternal deaths from unwanted pregnancies by increasing use of family planning (FP) methods and improving birth spacing practices. It stresses on increasing the use of long-term reversible and modern spacing methods as intrauterine devices (IUCDs) and injectables while offering various family planning services and products through social franchise and social marketing module. The project Ujjwal survey was conducted in 2014 with similar sampling technique to NFHS surveys and data on currently married fecund women were used for the present study.

\section{Outcome variables}

Contraceptive Use: The current use of contraception reported by women was categorised into different categories. Those women who are not using any contraception is categorised into "0 or Non-users", those who are using male and female sterilization (either husband or she is sterilized) are considered as " 1 or permanent method users", the women or her husband using temporary methods like Pills, Condoms, IUD, Injectables or any other modern temporary methods is categorized to " 2 or Users of spacing methods" and those who are using traditional methods like rhythm, withdrawal or any other traditional methods are considered as "users of traditional methods". In case of user of multiple methods, the more effective method was considered.

\section{Main predictors}

The main predictors used in the study were: Age of women, educational attainment, urban-rural residence, wealth status, caste, religion and sources of contraception.

Age of Respondent: The survey has collected information on each single age in the reproductive span of ever married women from 15 to 49 years. In this study, three-category of age of respondent variable used, by merging 15 to 24 years as 'one', 25 to 35 years as 'two' and $35+$ years as 'three'.

Educational attainment: Information on four educational i.e. no education, primary, secondary and higher level was collected in the NFHS third round were used in this study.

Locality of residence: The NFHS and Ujjwal baseline survey followed the Census of India definition to demarcate the urban and rural areas in the survey for this study.

Household wealth quintile: In the different round of the NFHS, a wealth index was computed by using Principal Component Analysis (PCA) based on an arbitrary scoring of household economic indicators such as housing quality, household amenities, size of landholding, and consumer durables etc and this index was divided into five quintiles (poorest, poorer, middle, richer, and richest). This wealth index is increasingly used to measure household economic status in large-scale household surveys $[17,18]$. In the present study, therefore, a separate wealth index, which is based on a set of selected household economic proxies, is computed for the states using both the NFHS and Ujjwal Survey data by using the Principal Component Analysis. The wealth index was subsequently divided into five quintiles - poorest, poorer, middle, richer, and richest. This was done to make the estimates comparable over all three NFHS rounds and Ujjwal Survey.

Caste: The caste of a respondent was based on the person's women's self-identification of their caste which was classified into Scheduled Castes (SCs), Scheduled Tribes (STs), Other Backward Castes (OBCs), and other castes based on the Constitution of India segregation social groups. The NFHS-1 did not provide information on OBCs. Due low sample size of STs in Bihar, the category was dropped for the analysis.

Religion: Religious groups were divided into three categories: Hindus, Muslims, and Others (religious groups that were neither Hindu nor Muslim).

Public-Private sources of contraception: In National Family Health Surveys and the Project Ujjwal Survey, the clients/ respondents were asked about the last source of obtaining contraception. Those who obtained from any public hospitals/ centers like government hospitals, urban health centers, primary 


\section{Global Journal of Reproductive Medicine}

health centers, community health centers, sub-centers/Midwives, Government mobile clinic/camp, Anganwadi (ICDS) centers etc are considered as 'user of public sources', who obtained from any private sources like private medical, clinics, pharmacy/drug store, private mobile clinic/camp etc are treated as 'users from private sources' and those who obtained products from friends/neighbours, husband, or don't know the source are considered as "others". Further, District level household

Results and facility survey (DLHS-III, 2007-08) data was used for comparison public-private sector contribution in both the states. Both bivariate and multivariate analysis was used to understand the changes in different methods and factors associated with the methods. Multivariate logistic regression analysis was used to identify factors associated with the use of contraceptive methods and the predicted probabilities of use in different methods due to nature of dependent variable which is of multiple categories.

\section{Trends of contraceptive use and method mixing}

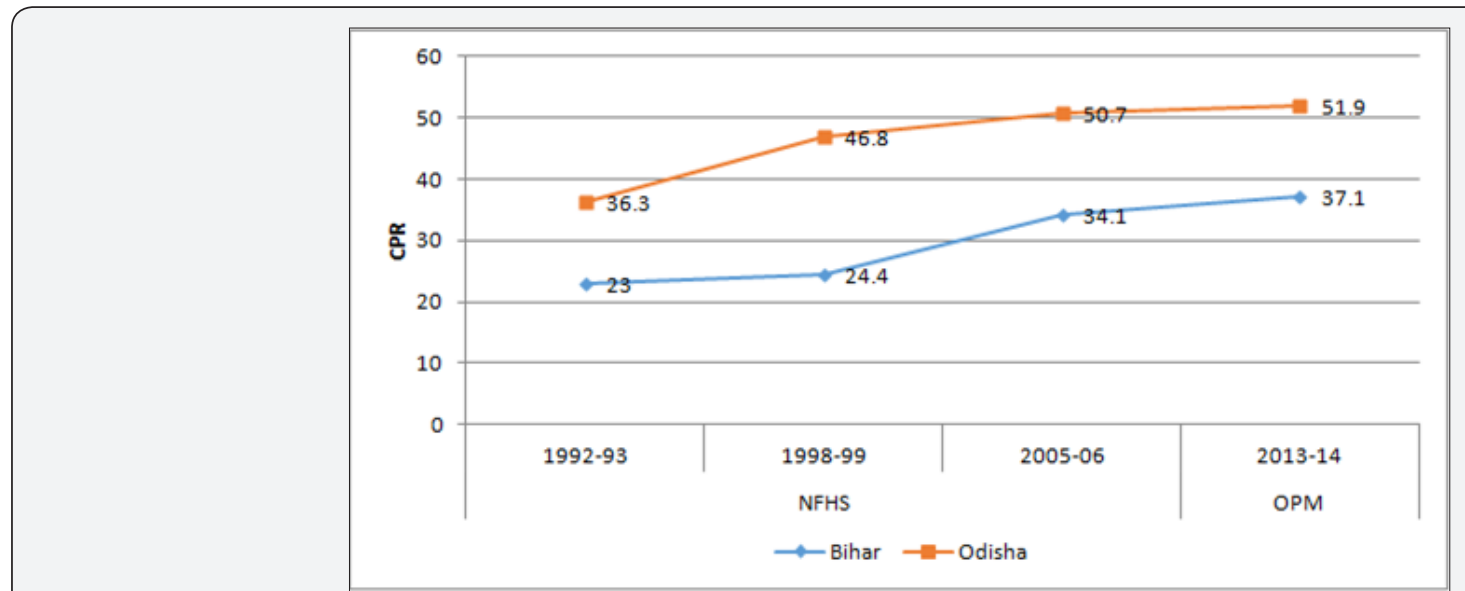

Figure 1: Trends in Family Planning Use in Bihar and Odisha.

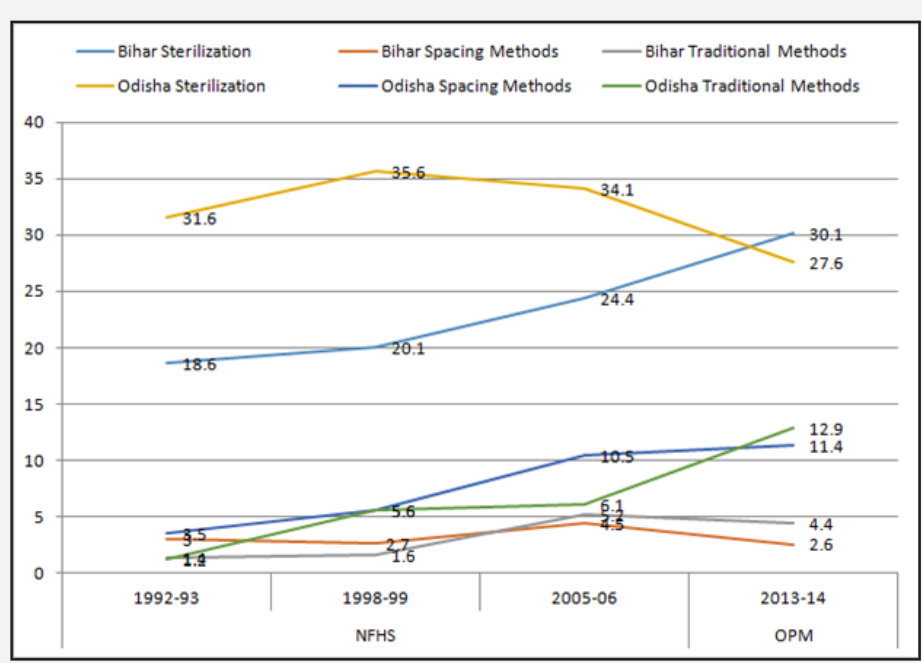

Figure 2 : Trends in Method Mix in Bihar and Odisha.

The results indicate that there is an increase in contraceptive prevalence rate (CPR) both nationally (1992-2006) and in both the states (1992-2014). In Bihar, the CPR has increased from 23 in 1992 to 37 percent in 2014 and in Odisha, it rose 52 percent in 2014 from 36 percent in 1992 respectively (Figure 1). Figure 2 shows trends in method mix in family planning in Bihar and Odisha. The result shows a steady increase in spacing (modern) methods in Odisha largely contributing to its increase in CPR whereas in Bihar the spacing method is low and doesn't show a clear pattern. The use of limiting methods/sterilization increased in Bihar during the last two decades (1992-2014), whereas; it has gone down in Odisha. The data shows that the proportion of sterilization of the total CPR remains around 80 percent during 1992-2014 in Bihar; whereas it has gone down to 53 percent in 2014 in comparison to 87 percent in 1992 . This reflects that method mixing has been more prominent is Odisha in comparison to Bihar. Traditional methods are higher sides and caste plays an important role in use of family planning methods 


\section{Global Journal of Reproductive Medicine}

in Odisha. Odisha has higher proportion of Scheduled Castes and tribe population.

\section{Socio-economic differentials in contraceptives uses}

The change in the relative mix of spacing and limiting methods in Bihar and Odisha during 1992-2014 is presented in Table 2. The use of methods for spacing has increased among women of all age groups in Odisha. This is high (17\%) among the women aged between 25-34 years. Similarly, the use of limiting methods is high among women above 35 years in Odisha and additionally it is increasing trend during 22 years period among all age groups as women from younger age preferring to spacing methods. In Bihar, limiting methods have only increased among the women with above 35 years of age. In rural areas, both spacing and limiting methods have gone up in Bihar. On the other hand, in Odisha the trend shows a decline in the use of limiting methods and increasing preferences of spacing methods during the given period in both rural and urban area (Table 2). Interestingly, the use of spacing methods only rose among the Non-Scheduled Castes and Tribes social groups (OBCs \& Others) who mostly stay rural and remote area of the state. Conversely, in Bihar it has gone up among scheduled caste group.

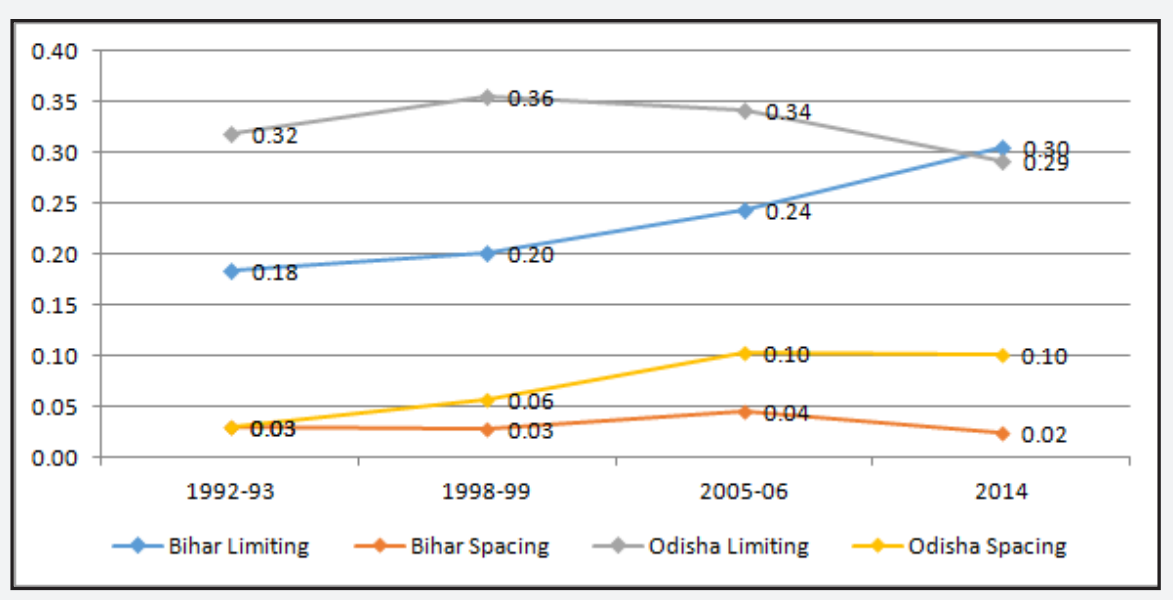

Figure 3 : Probabilities of Limiting and Spacing Methods in Bihar.

Table 2: Changes in Spacing and Limiting Methods by Socio-demographic characteristics in Bihar and Odisha.

\begin{tabular}{|c|c|c|c|c|c|c|c|c|}
\hline \multicolumn{9}{|c|}{ Bihar } \\
\hline & \multicolumn{4}{|c|}{ Spacing } & \multicolumn{4}{|c|}{ Limiting } \\
\hline & 1992-93 & 1998-99 & 2005-06 & 2014 & 1992-93 & 1998-99 & 2005-06 & 2014 \\
\hline \multicolumn{9}{|c|}{ Age of women } \\
\hline $15-24$ & 2.4 & 1.3 & 4 & 1.9 & 2.1 & 2.6 & 5.3 & 5.3 \\
\hline $25-34$ & 4.4 & 4.4 & 5.6 & 4.2 & 22.7 & 22.1 & 29.1 & 29 \\
\hline $35+$ & 1.8 & 2.4 & 3.8 & 1.5 & 33.2 & 36.3 & 39.1 & 43.1 \\
\hline \multicolumn{9}{|l|}{ Residence } \\
\hline Urban & 8.6 & 7.4 & 9.2 & 7.6 & 30.8 & 28.3 & 31.9 & 32.5 \\
\hline Rural & 2 & 2.2 & 3.7 & 3.8 & 16.6 & 19.2 & 23.1 & 30.6 \\
\hline \multicolumn{9}{|l|}{ Caste } \\
\hline SC & 1 & 1.7 & 2.5 & 3.6 & 12.4 & 16.4 & 17.3 & 30.7 \\
\hline $\mathrm{OBC}$ & NA & 2.7 & 4.1 & 4 & NA & 20.1 & 26.2 & 31.8 \\
\hline Other & 3.3 & 3.7 & 7.3 & 5.5 & 19.9 & 29 & 25.6 & 27.6 \\
\hline \multicolumn{9}{|c|}{ Odisha } \\
\hline \multicolumn{9}{|c|}{ Age of women } \\
\hline $15-24$ & 2.9 & 4.8 & 10.3 & 13.2 & 8.1 & 6.9 & 4.6 & 5.2 \\
\hline $25-34$ & 4.5 & 7.6 & 16 & 17 & 36.5 & 37.4 & 30.6 & 30.1 \\
\hline $35+$ & 1.2 & 3.8 & 4.9 & 5.6 & 49.3 & 55.5 & 56.3 & 56 \\
\hline \multicolumn{9}{|l|}{ Residence } \\
\hline Urban & 8 & 13.6 & 18.5 & 15.3 & 37.3 & 32.8 & 31.3 & 25.4 \\
\hline
\end{tabular}


Global Journal of Reproductive Medicine

\begin{tabular}{|c|c|c|c|c|c|c|c|c|}
\hline Rural & 2.2 & 4.6 & 8.9 & 9.3 & 30.7 & 35.9 & 34.7 & 29.7 \\
\hline Caste & & & & & & & & \\
\hline SC & 1.4 & 2.5 & 10.3 & 8.8 & 30.4 & 36.6 & 35.9 & 31.4 \\
\hline ST & 1.3 & 2.8 & 4.5 & 6.8 & 27.6 & 30.4 & 25.5 & 26.2 \\
\hline OBC & NA & 5.8 & 9 & 10.9 & NA & 35.3 & 37.7 & 30.1 \\
\hline Other & 3.8 & 9.5 & 15.6 & 13.7 & 33.2 & 38.7 & 36.5 & 26.4 \\
\hline
\end{tabular}

The multivariate analysis shows the predicted probability of women choosing spacing methods has gone up in both the states after adjusting for socio-economic variables such as religion, caste, education, and age of women. The probability of using modern spacing method is lowest among Muslims, poor and older women in both the states. The trend of contraceptives use also shows a similar trend in Bihar and Odisha after adjusting it for socio-economic variables such as religion, caste, education, and age of women (Figure 3).

\section{Public private partnership in use of spacing and limiting methods}

Comparing with District Level Household and Facility Survey (DLHS-III, 2007-08) with Ujjwal household survey data, it is found that the proportion of CPR from government clinic sources has marginally increased Bihar (21.7\% to $22.1 \%)$ and declined in Odisha (30.5\% to 28.1\%) in Bihar during 2007-14 (Figure 4). Additionally, the contribution of private sector almost doubled in during these 7 years between both the surveys. While the private sector largely contribute to three-fourth of spacing methods, the government sector contributes almost two-third sterilization in Bihar (Figure not shown). Nevertheless, there is a steady increase in both private sector contributions to the uptake of both spacing and limiting methods.

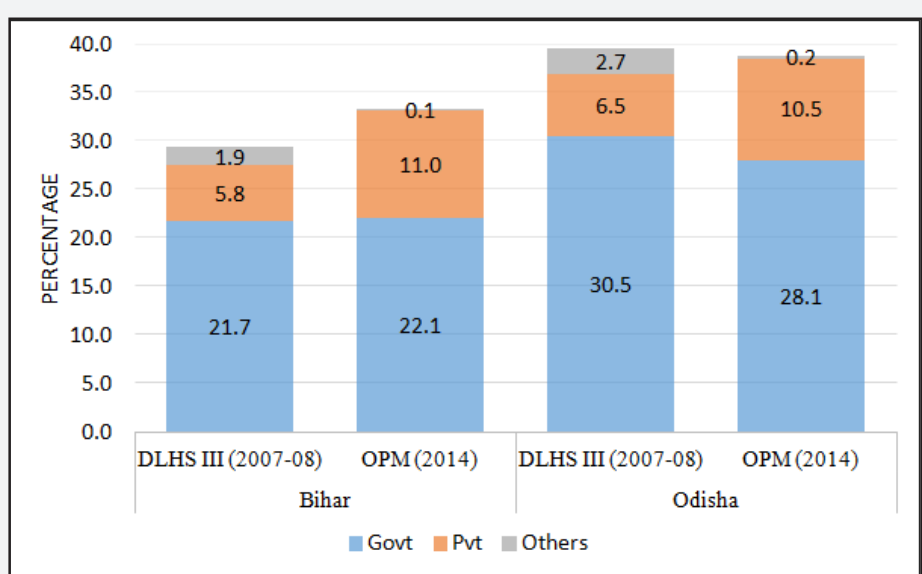

Figure 4 : Contributions by Public-Private sector in Modern Contraceptives in Bihar and Odisha.

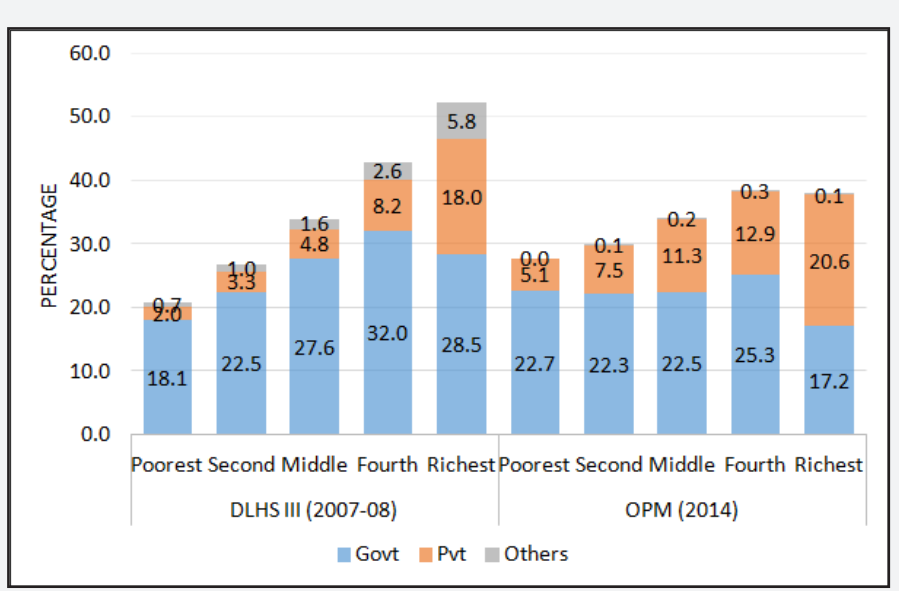

Figure 5 : Current Use of Modern Contraceptives by Household Wealth Quintile in Bihar. 


\section{Wealth quintiles and ppp in family planning}

Most studies have found a strong association between wealth quintiles and modern contraceptive use and it is critical to family planning policies of India [19,20]. There are many studies which found contraceptive use is higher among third/fourth wealth quintile. However a very few studies in India focused on market segmentation based on wealth quintile approach. The contribution of modern contraceptive use in Bihar and Odisha is shown in Figure $5 \& 6$ respectively. It is evident from the result that the more women are obtaining family planning methods from private sector with increase in economic status of women (fourth and fifth wealth quintiles) in both the states. In addition, the contribution of private sector has to family planning method is going up across all quintiles in Bihar. For the fifth/richest quintile, the private sector contributes more to its CPR than the government sector despite the fact the government-provided sterilization remains the most popular method.

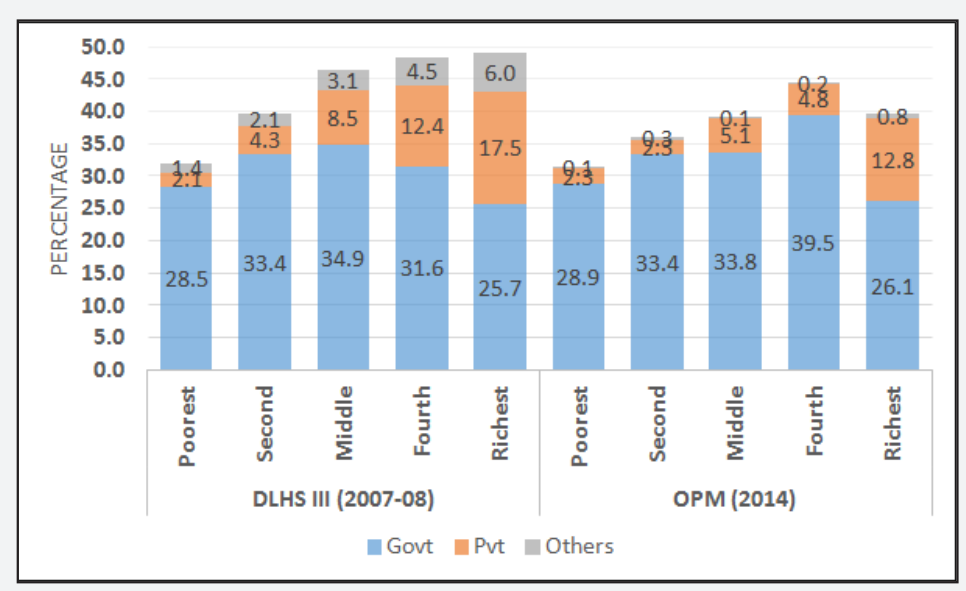

Figure 6 : Current Use of Modern Contraceptives by Household Wealth Quintile in Odisha.

\section{Discussion}

Family Planning Programmes improve maternal and child health through reduction in fertility (which reduces lifetime risk of maternal mortality) and reduce infant mortality through birth spacing. This paper brought out that although contraceptive prevalence is increasing in both the states, the increase is slow and is hampered by the poor method mix offered to couples. The limiting methods remains the most dominant method contributing to lion share of the modern CPR in Bihar, whereas the share of sterilization is going down in Odisha, resulting in increasing contraceptive prevalence and declining fertility in comparison to Bihar state. The increase in spacing methods provides the choice and addition to the contraceptive prevalence. Other studies in Bihar on Family Planning found that the met need for spacing methods is very small as compared to unmet need contributing to poor performance of family planning program in Bihar. It is because sufficient awareness has failed to provide people with enough choices and range of contraceptives for spacing. The family planning program in Bihar like many other states in India has primarily focused on sterilization and a sufficient method mix is not available in rural and remote places. Studies have shown that countries in which all couples have easy access to a wide range of contraceptive methods have a more balanced methods mix and higher levels of overall contraceptive prevalence than countries with limited access to various contraceptives [2,21]. Further, Jain [4] has estimated that the widespread addition of one method to options available in a country would be associated with an increase of $12 \%$ in contraceptive prevalence. A balanced method mix is also an indicator that there is no "systematic limitation of contraceptive choice" [22].

In Odisha, the spacing method is on rise among all age groups of women, place of residence and three social groups namely SCs, STs and OBCs which create a method mixing increasing the contraceptive prevalence rate in the state. However, there is also room for improvement increasing the availability of spacing methods as many of the couples use traditional method of contraception [23]. Further, in Bihar, the trend of methods used for spacing method is fluctuating by socio-economic characteristics. It also exhibits a nominal increase in the rural areas and among scheduled caste population. This increase can be attributed some the programmes run by national and international agencies through social marketing in rural areas. However, the highest fertility in the state and higher unmet need for family planning needs a greater intervention to increase contraceptive rate in the state, thereby partly curtailing maternal and child mortality in the state [24].

The wealth quintile analysis indicates an increased use of the private sector by the users in Bihar especially among richer and richest wealth quintiles. Although family planning in India centred towards government programmes, this trend towards private sector cannot be ignored owing to low capacity of public distribution system. The ability and intention to pay makes 


\section{Global Journal of Reproductive Medicine}

the richer groups more include to use the private sector due to better service quality and duration of time spent for obtaining the services. The carrying capacity and quality of infrastructure in the public sector, social marketing by private sector agencies and increase in quality of health care may be attributed to this change among people who are ready to pay. One of the most important and successful models in this regard is total market approach adopted by different government and private agencies of providing rebate to people from lower economic strata and making people pay for higher economic strata. There are many studies in south-east Asia and Latin American countries which show total market approach can be effective measures in family planning $[13,14]$. Project Ujjwal sponsored by UK Aid and lead by Palladium under public-private partnership programmes have enhanced capacity of several clinics in both states following a total market approach $[25,26]$.

The project provided support to rural clinics in Bihar and Odisha which promoted in both spacing and limiting methods. Expert visits and suggestions, infrastructure development, motivation through media and motivators and financial consultation was suggested and promoted which increased capacity building of the clinics resulting in increasing the clients. It has not only enhanced the capacity of clinics but also contributed the use of both limiting and spacing methods contraceptive in both states through social franchises of the network and social market within and outside the network. For example, in two and half year of the project the franchise clinics were able to conduct more than hundred thousand sterilization, sold around 40 thousand injectables, more than two hundred thousand IUDs and sold 25 million condoms at a very minimal rate. The people below poverty line (BPL) were provided the services at free of services on a fixed day [27].

\section{Conclusion}

The National Population Policy of Government of India (NPP, 2000 ) focuses on reduction of the unmet need of family planning. However, unmet need in the states like Bihar is still very high.The FP programmes focus on spacing methods in Odisha has made a steady progress in contraceptive use and reduced in a decline in unmet need for family planning, thereby, bringing Odisha near to population stabilization. There is need for public-private partnership for family planning through visionary leadership, social entrepreneurship and relationships based on trust between the stakeholders which are important for successful partnerships in Bihar. The initiatives by NGOs and experiments with public-private partnerships are contributing to increase in spacing methods. The social marketing and social franchising of selected reproductive health services by DFID sponsored project Ujjwal is one such example. These organisations have largely contributed to increase in injectable users special in Bihar to which now government has included under its family planning programme. Capacity of private partners and public sector towards managing the partnerships needs to be fully developed. Any policy initiatives to strengthen the flagging public sector family planning services is always a positive step but a government might fail to deliver quality social services due to lack of basic infrastructural capacity. This can be addressed through strengthening clinical or non- clinical services of family planning through private sector capacity building.

\section{References}

1. Díaz M, Simmons R, Díaz J, Gonzalez C, Makuch M, et al. (1999) Expanding contraceptive choice: findings from Brazil. Stud Fam Plann 30(1): 1-16.

2. Magadi MA, Curtis SL (2003) Trends and determinants of contraceptive method choice in Kenya. Studies in family planning 34 (3): 149-159.

3. Ross J, Stover J (2013) Use of modern contraception increases when more methods become available: analysis of evidence from 19822009. Glob Health Sci Pract 1(2): 203-212.

4. Jain AK (1989) Fertility reduction and the quality of family planning services. Stud Fam Plann 20(1): 1-16.

5. Potter RG (1971) Inadequacy of a one-method family planning program. Stud Fam Plann 2(1): 1-6.

6. Singh A, Ogollah R, Ram F, Pallikadavath S (2012) Sterilization regret among married women in India: implications for the Indian national family planning program. Int Perspect Sex Reprod Health 38(4): 187195.

7. Peterson HB, Xia Z, Hughes JM, Wilcox LS, Tylor LR, et al. (1997) The risk of ectopic pregnancy after tubal sterilization. N Engl J Med 336(11): 762-767.

8. International Institute for Population Sciences (IIPS) (2010). District Level Household and Facility Survey (DLHS-3), 2007-08: India. Mumbai: IIPS

9. Prusty RK (2014) Use of contraceptives and unmet need for family planning among tribal women in India and selected Hilly states. J Health Popul Nutr 32(2): 342-355.

10. Iyer S (2002) Religion and the decision to use contraception in India. Journal for the Scientific Study of Religion 41(4): 711-722.

11. Bradley SEK, Croft TN, Fishel JD, Westoff CF (2012) Revising unmet need for family planning.DHS Analytical Studies No. 25, Calverton, MA: ICF International.

12. Campbell OM, Graham WJ, Lancet Maternal Survival Series steering group (2006) Strategies for reducing maternal mortality: getting on with what works. The lancet 368(9543): 1284-1299.

13. Drake JK, Espinoza H, Suraratdecha C, Lacayo Y, Keith BM, et al. (2011) Stakeholder perceptions of a total market approach to family planning in Nicaragua. Rev Panam Salud Publica 29(5): 329-336.

14. Drake JK, Thanh LHT, Suraratdecha C, Thu HPT, Vail JG (2010) Stakeholder perceptions of a total market approach to family planning in Viet Nam. Reproductive Health Matters 18(36): 46-55.

15. Ram F, Roy TK (2004) Comparability issues in large sample surveyssome observations. In: Roy TK, et al. (Eds), Population, health and development in India-Changing Perspectives, International Institute for Population Sciences, Mumbai. Rawat Publications, New Delhi, India p. 40-56.

16. International Institute for Population Sciences (IIPS) \& ORC Macro (2007). National Family Health Survey, India 2005-06: All India. Mumbai: International Institute for Population Sciences, Mumbai, India. 
17. Filmer D, King EM, Pritchett L (1998) Gender disparity in South Asia: comparisons between and within countries. Policy Research Working Paper No. 1867.Washington, DC: World Bank.

18. Montgomery MR, Gragnolati M, Burke KA, Paredes E (2000) Measuring living standards with proxy variables. Demography 37(2): 155-174.

19. Gakidou E, Vayena E (2007) Use of modern contraception by the poor is falling behind. PLoS Med 4(2): e31.

20. Creanga AA, Gillespie D, Karklins S, Tsui AO (2011) Low use of contraception among poor women in Africa: an equity issue. Bulletin of the World Health Organization 89(4): 258-266.

21. Ross J, Hardee K, Mumford E, Eid S (2002) Contraceptive Method Choice in Developing Countries. International Family Planning Perspectives $28(1)$.

22. Sullivan TM, Bertrand JT, Rice J, Shelton JD (2006) Skewed contraceptive method mix: why it happens, why it matters. J Biosoc Sci 38(4): 501-21.
23. Census of India (2011) Provisional population tables, Series 1 Registrar General and Census Commissioner, India.

24. Ram F, Shekhar C, Chowdhury B (2014) Use of traditional contraceptive methods in India \& its socio-demographic determinants. Indian J Med Res 140(Suppl 1): S17.

25. State Domestic Product and other aggregates, 2004-05 series (2015) Ministry of Statistics and Programme Implementation.

26. Seiber EE, Bertrand JT, Sullivan TM (2007) Changes in Contraceptive Method Mix In Developing Countries. International Family Planning Perspectives 33(3): 117-123.

27. United Nations, Department of Economic and Social Affairs, Population Division (2015). Trends in Contraceptive Use Worldwide 2015 (ST/ ESA/SER.A/349).

\section{Your next submission with Juniper Publishers will reach you the below assets}

- Quality Editorial service

- Swift Peer Review

- Reprints availability

- E-prints Service

- Manuscript Podcast for convenient understanding

- Global attainment for your research

- Manuscript accessibility in different formats

( Pdf, E-pub, Full Text, Audio)

- Unceasing customer service

Track the below URL for one-step submission https://juniperpublishers.com/online-submission.php 